\title{
Studies of behaviour of the automatic control system of roadheader cutting heads movement
}

\author{
Piotr Cheluszka ${ }^{1, *}$, Piotr Sobota ${ }^{1}$, and Grzegorz Głuszek ${ }^{1}$ \\ ${ }^{1}$ Silesian University of Technology, Faculty of Mining and Geology, Department of Mining Mechanization and Robotisation, \\ Akademicka 2, 44-100 Gliwice, Poland
}

\begin{abstract}
Boom-type roadheaders are basic machines used in underground mines for drilling roadways, in tunnelling and also for making underground buildings using trenchless methods. The article presents selected results of tests carried out in a semi-industrial scale, on a roadheader R-130, concerning behaviour of an innovative solution of system for automatic control of boom-type roadheader cutting heads' movements. This important innovation, not known before in mining cutting machines, is the software control of cutting heads angular speed using a frequency converter. The text shows an impact of key values, from a perspective of an assumed control purpose, of programming device (setting system) parameters, achieving reference values for the actuators, on controlled facility behaviour when cutting a layered cement and sand block. The performance of the automatic control system without and with feedback to the setting system concerning an actual speed of cutting heads movement, which is important from the control system hardware perspective, was compared.
\end{abstract}

\section{Introduction}

Boom-type roadheaders (Fig. 1) are widely used in underground mining of mineral resources for cutting roadways and chambers. They are employed also to a certain extent in engineering works for making underground buildings using trenchless methods (e.g. tunnels for traffic, hydro-technical purposes or technological and other chambers, metro stations, underground garages etc.). Those are multipurpose machines, but their major task is mechanical cutting of rock in the heading face of the roadway, tunnel or chamber [1].

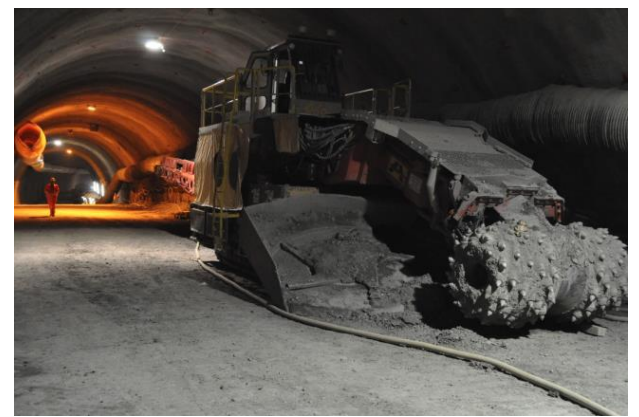

Fig. 1. Boom-type roadheader MT720 (by Sandvik) when drilling Markovec tunnel in Slovenia [2]

A condition necessary to ensure high efficiency of mechanical rock cutting with roadheaders is, besides appropriate construction of cutting tools (picks), working units and machines themselves, an optimised cutting process, considering ongoing conditions of its performance. Optimisation entails the need to automate the roadheader operations. For the manual control, the choice of the cutting process parameters' values is not optimum as it is based on a subjective assessment of the process course by an operator. This is why research and development works have been carried out for many years to automate and robotise cutting machines used in mining [3-6] and engineering works (in road construction and civil engineering) [7]. An important aspect which must be solved here is efficient automatic control of cutting process parameters, ensuring the efficient and energy-saving roadheader operation [8]. This refers primarily to the situation when the rock workability in the heading face of the drilled roadway or tunnel is highly diverse and changes along it. Hence, natural factors influence cutting process efficiency (drilling progress) and its energy consumption to a significant degree. They affect also the strain of the cutting machine, determining its durability and reliability $[9,10]$.

An efficient algorithm for controlling the rock cutting process parameters with a boom-type roadheader was designed by the Research Team from the Department of Mining Mechanization and Robotisation of the Faculty of Mining and Geology at the Silesian University of Technology in cooperation with Famur Institute and FAMUR S.A., a leading global manufacturer of mining machines and, consequently, of boom-type roadheaders. Within the research project carried out in 2015-2017, broad theoretical studies (using original mathematical models) and experimental studies on an actual facility (roadheader R-130) were carried out. Conclusions

* Corresponding author: Piotr.Cheluszka@ polsl.pl 
derived from those studies led to the development of a structural solution for the cutting heads automatic control system where the original algorithm for the cutting process parameter control was used. An innovation of this solution lies in the programme control of the roadheader cutting heads angular speed. For that purpose, a frequency inverter supplying the main roadheader motor was used. The inverter is controlled by a master controller where the programming device (setting system) develops control signals depending on a dynamic load of the cutting heads drive. This article presents selected results of tests of that system carried out on a dedicated experimental stand (Fig. 2).

a)

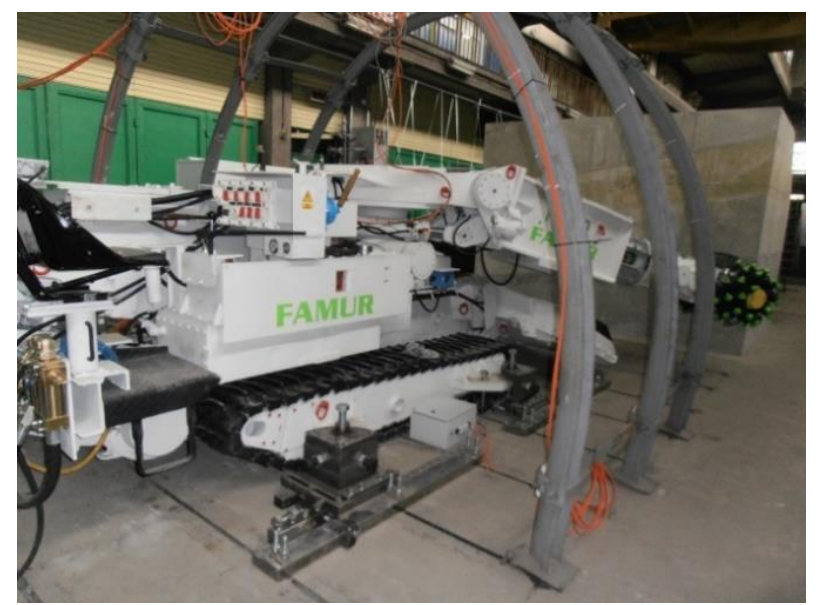

b)

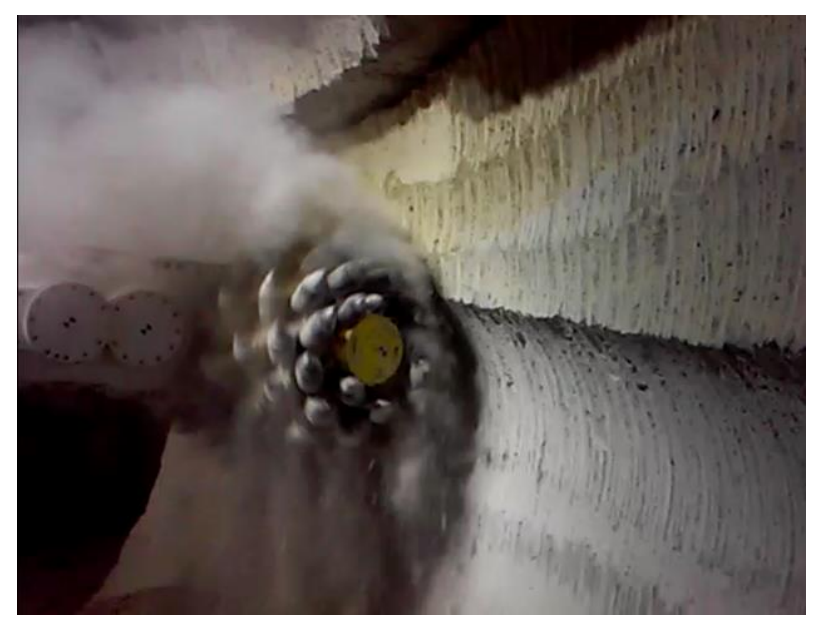

Fig. 2. Roadheader R-130 on the test stand in the technological hall of the Faculty of Mining and Geology at the Silesian University of Technology (a) and the course of cutting the surface of the cement and sand block in the automatic mode (b).

\section{Brief characteristics of the automatic cutting process parameter control method}

Cutting the heading face surface with a roadheader is carried out basically when moving cutting heads parallel to the floor. Control of the rock cutting process is reduced to pre-setting (manual or automatic) of the parameter values for this process (Fig. 3):
- web of cut $z[\mathrm{~mm}]$ - resulting from displacement of the roadheader to the heading face,

- cut height $h[\mathrm{~mm}]$ - understood as the height of the cut layer,

- cutting heads angular speed $\dot{\varphi}_{G}[\mathrm{rad} / \mathrm{s}]$

- cutting heads movement speed vow [mm/s] resulting from boom deflexion velocity in a plane parallel to the floor.

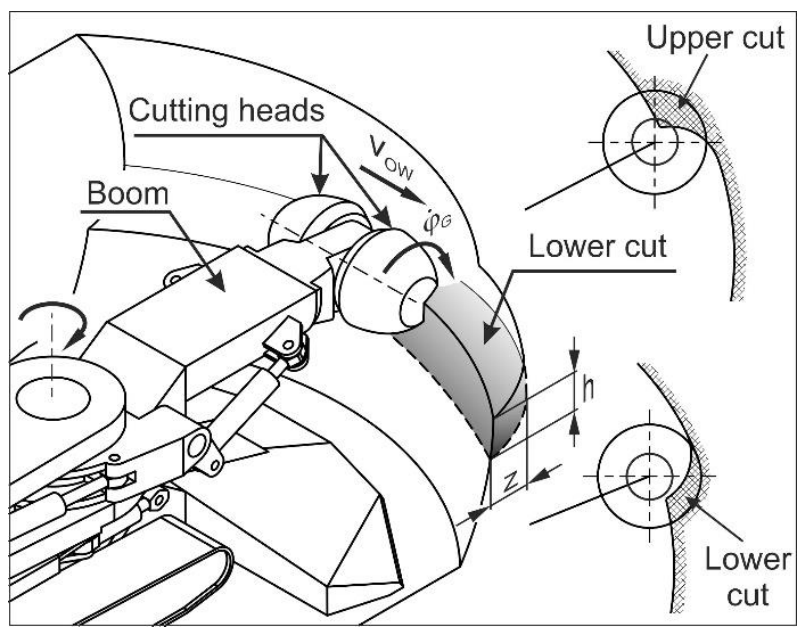

Fig. 3. Parameters of the cutting process with a boom-type roadheader: $z$-web of cut; $h$ - cut height; $\dot{\varphi}_{G}$, vowrespectively: angular and movement speed of cutting heads.

In the developed solution of the automatic control system three out of the above cutting process parameters are changed by the programme $\left(h, \dot{\varphi}_{G}\right.$ and $\left.v_{O W}\right)$. The cut height $h$ results from the boom deflexion angle in the plane perpendicular to the floor $\alpha_{V}$. The angular speed of cutting heads $\dot{\varphi}_{G}$ depends on the supply voltage frequency $f$. On the other hand, the cutting heads movement speed $v_{O W}$ is controlled by opening the electro-hydraulic valve in the supply system for the boom rotation actuators (characterised by a valve opening coefficient $k_{D O}$ ). The control purpose is to minimize the dynamic load of the cutting heads drive and energy consumption of cutting. The parameters characterising the cutting system dynamic load (mean torque on a motor shaft $M_{m}$, frequency of exceeding the assumed permissible limit by the torque $M_{p}$ ) and mean energy consumption of cutting expressed by $W E$ :

$$
W E=\frac{100 \cdot M_{m} \cdot f}{h \cdot k_{D O}} ;[\mathrm{Nm} \cdot \mathrm{Hz} / \mathrm{mm}]
$$

where:

$M_{m}-$ mean torque value on the motor shaft $[\mathrm{Nm}]$,

$f-\quad$ power supply frequency $[\mathrm{Hz}]$,

$h$ - cut height [mm],

$k_{D O}$ - opening coefficient of the electro-hydraulic valve in the boom swinging drive [\%].

are determined at time intervals corresponding to the periods of consecutive rotations of cutting heads based on motor load measurements and information on parameter values used for cutting. The dynamic load condition of the cutting heads drive, being a measure of 
the roadheader dynamic load, is qualified based thereon into one of five cases (excessive load, underload, nominal load, dynamic overload and low energy consumption). The criteria for classification of the dynamic load of the cutting systems into particular cases were described in [11]. The programming device develops reference values $(R E F)$ of cutting process parameters for consecutive rotations of cutting heads based on the strategy assumed for particular load cases. In the developed solution, the web of cut $z$ is not controlled. This results from the method of pre-setting it used for most roadheaders. This is done as a result of the roadheader approaching the heading face in the course of cutting heads' sumping. In such circumstances, controlling the web of cut value would require monitoring the roadheader in the roadway. Adjusting the value of this parameter would be connected, on the other hand, with the need to move the whole machine. This is why the web of cut is considered a random variable. Similarly, the initial value of the cut height $h$ (at the beginning of every cut made parallel to the floor) is also stochastic. It is, however, adjusted as the cutting heads move, as a result of changing boom deflexion angle in the plane perpendicular to the floor $\alpha_{V}$. Operation of the discussed automatic control system consists in developing the required (reference) cutting process parameter values in the course of the cutting heads movement (Fig. 4):

$>f_{R E F}$ - supply voltage frequency of the motor in the cutting system, determining the cutting heads angular speed $\dot{\varphi}_{G R E F}$,

$>h_{R E F}$ - height of the cut being the basis for determining the required value of the boom deflexion angle $\alpha_{V R E F}$ and

$>V_{O W R E F}$ - cutting heads movement speed, being grounds for determining the opening degree of the electro-hydraulic valve in the supply system of the boom rotation actuator $k_{D O R E F}$.

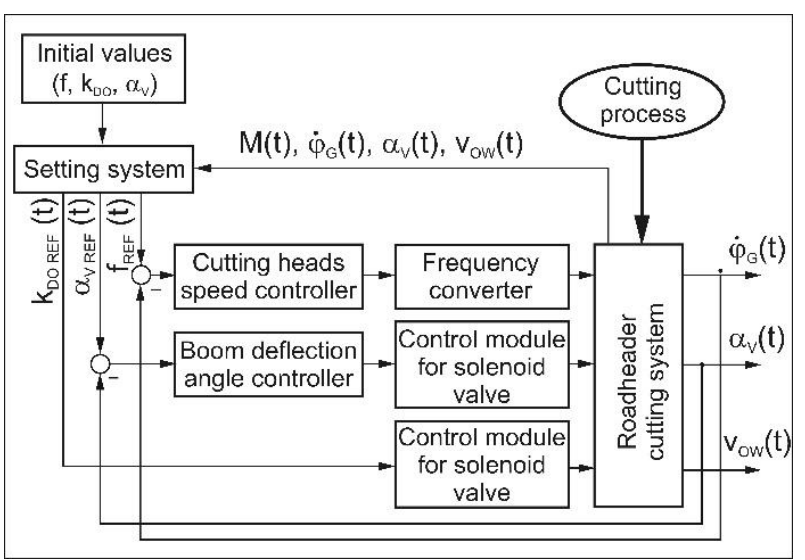

Fig. 4. Simplified flow chart of the automatic control system controlling the movement of roadheader cutting heads.

The said values are determined based on the cutting system response to the cutting process performance with the ongoing values of the process parameters. The value controlled is the dynamic load of the cutting heads drive, measured by the torque on the motor shaft $M$. The programming device is timed with the interval corresponding to the ongoing interval of the cutting heads rotation [11]. This makes the control system independent of fast-changing torque runs in the cutting heads drive, caused by high dynamics of the cutting process. What is more, actuating devices have time to implement the values developed by the programming device (setting system).

Controlling two out of three cutting process parameters (supply voltage frequency of the main motor $f$ and boom deflexion angle in the plane perpendicular to the floor $\alpha_{V}$ ) takes place in a closed feedback loop using the respective controllers: PI and P. On the other hand, the cutting heads movement speed $v_{O W}$ is controlled in an open feedback look by pre-setting the electro-hydraulic valve opening degree.

\section{Testing the automatic control system on an actual facility}

The usefulness of the developed technical solution was tested on a test stand with roadheader R-130 manufactured by FAMUR S.A. The surface of cement and sand block was cut. The block comprises five layers inclined $10^{\circ}$ to the floor, with uniaxial compressive strength $(U C S)$ of 33 to $69 \mathrm{MPa}$. Cuts parallel to the floor were made. The tested properties included behaviour of the automatic control system when cutting with differing web of cut, initial cut height value, for varying boom deflexion in the plane perpendicular to the floor. Because of the oblique location of the cement and sand block layers, the workability of the cut material varied along the cut length which was an important cause of the cutting process performance conditions.

One of the test stages of the developed automatic control system was the determination of the programming device settings. The said values were compared with the actual parameter values describing the dynamic cutting system load at the decision-making stage when the cutting parameters are selected based on the assumed control criteria. As indicated by broad simulation studies, being grounds for developing the discussed automatic control algorithm, setting system behaviour should depend on the cutting heads movement speed $v_{O W}$ [12]. This is why certain ranges of that speed are analysed where the reference cutting process parameter values are developed using various strategies. As the boom deflexion velocity control is carried out in the open feedback loop, it was checked if the actual value of that velocity $\left(v_{O W}\right)$ follows the reference one (vOW REF).

Figure 5 presents the course of reference and actual cutting process parameter values when making the upper cut (see Fig. 3) with the web of cut $z=200 \mathrm{~mm}$ and the initial cut height $h=150 \mathrm{~mm}$. The boom was turned to the right, within the boom deflexion angle in the plane parallel to the floor $\alpha_{H}$ from $-27^{\circ}$ to $+36^{\circ}$ (Fig. 5b). The initial value of the boom deflexion angle in the plane perpendicular to the floor was $\alpha_{V}=-4^{\circ}$. Cutting started in 14th second of the test when the setting system increased the opening degree of the valve supplying the boom rotation actuator $k_{D O R E F}$, causing gradual increase in the boom deflexion speed. In 19th second the 
reference value of that velocity ( voW REF ) reached 150 $\mathrm{mm} / \mathrm{s}$ (Fig. 5a). The cut height $h$ changed only slightly here. At the same time, the programming device increased the supply voltage frequency for the motor in the roadheader cutting system $\left(f_{R E F}\right)$ from 35 to $50 \mathrm{~Hz}$ (Fig. 5b). Growth in the boom deflexion velocity was accompanied by growth in the torque at the motor shaft in the cutting heads drive, causing performance of various procedures by the programming device for: Case no. 2 (underload), as $M_{m}<0.8 M_{n}$ and Case no. 3 (nominal load), for which $M_{m}=(0.8 \div 1.2) M_{n}$ (Fig. 5c).

a)

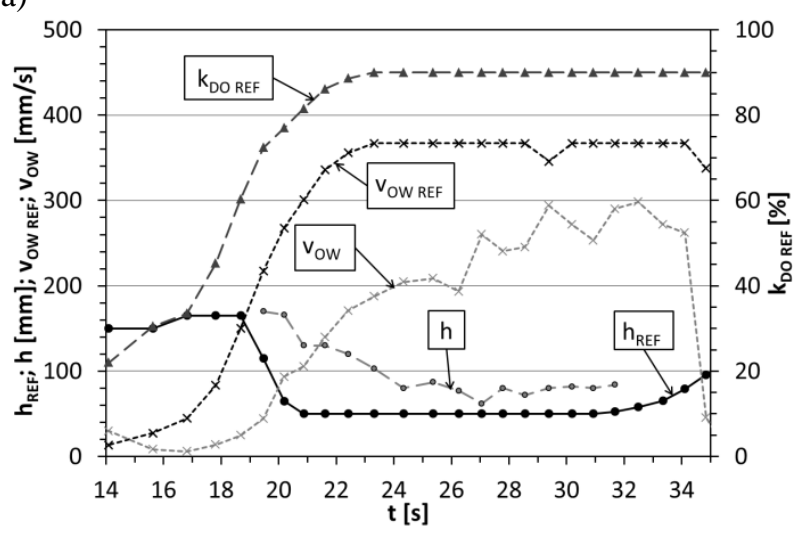

b)

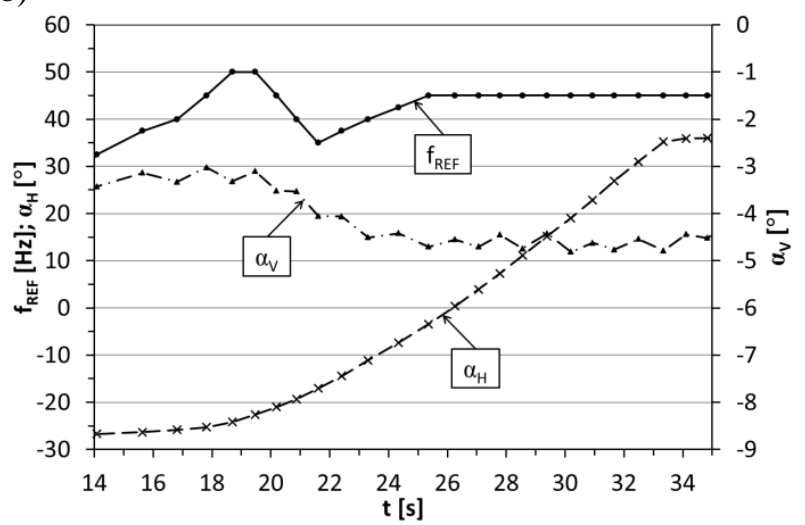

c)

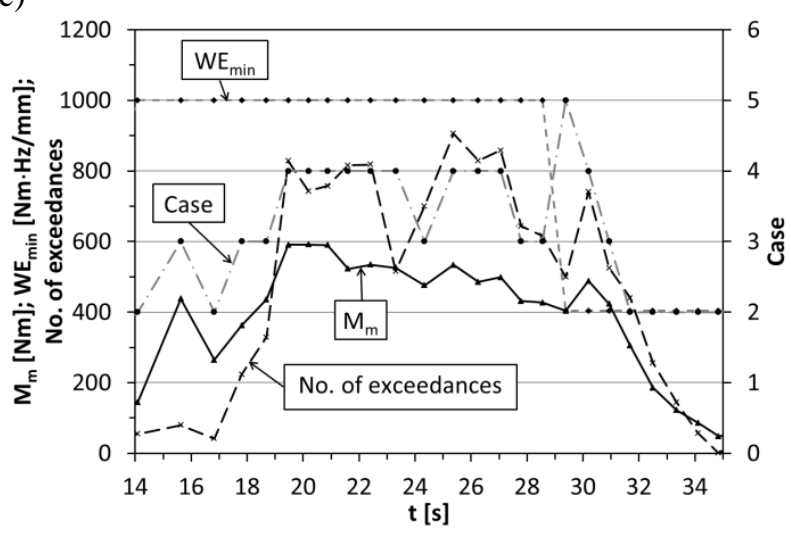

Fig. 5. Plot of cutting process parameter values developed by the setting system and behaviour of the tested roadheader when cutting in the automatic mode.

The programming device kept increasing the developed value of the boom deflexion and, consequently, the opening degree of the valve supplying the boom rotation actuator to the maximum value $k_{D O M A X}$ $=90 \%$ in 23rd cutting second. As a result of programmed opening of the electro-hydraulic valve, actual cutting heads movement speed $v_{O W}$ grew. This resulted in greater cutting resistance and consequent increase in the mean torque value $M_{m}$. Increased intensity of the cutting heads drive dynamic load was manifested by the increased number of exceeded torque threshold value. Consequently, the setting system implemented a procedure corresponding to Case no. 4 (dynamic overload), as the number of exceedances was higher than assumed, i.e. 500 (Fig. 5c). The programming device reduced the supply voltage frequency of the main roadheader motor to $f_{\text {REF }}=35 \mathrm{~Hz}$ (Fig. 5b) and the cut height to $h_{R E F}=50 \mathrm{~mm}$ (Fig. 5a). The result was the gradual decrease in the mean torque value on the motor shaft in the cutting system. During consecutive four seconds of cutting, the setting system increased the cutting heads angular speed as a consequence of increasing the reference frequency of the supply voltage frequency in the roadheader cutting system. As the movement speed of cutting heads vow reached a relatively high value, the dynamic drive load stabilised on the rated level. In 30th second of the test, because of high cutting efficiency and relatively low cutting heads drive load, the cutting process had low energy consumption (energy consumption coefficient $W E$ reached the minimum value). Hence, the programming device implemented the strategy for Case no. 5 (low energy consumption) consisting in retaining advantageous cutting process parameter values.

Comparing a plot of the reference value ( $V_{\text {OW REF }}$ ) and the actual value (vow) of the cutting heads movement speed values (boom deflection), significant discrepancies can be seen (Fig. 5a). The actual boom deflexion velocity was clearly lower than the value developed by the programming device (setting system). During the analysed cut, a maximum difference between the two speed values was as much as $195 \mathrm{~mm} / \mathrm{s}$ in 22nd second of cutting and ca. $70 \mathrm{~mm} / \mathrm{s}$ in the final phase of cut. This disturbs operation of the automatic control system as the selection of algorithm procedures carried out by the setting system depends, among others, on the range of the boom deflexion velocity. Therefore, it is indispensable to ensure the signal of the actual boom deflexion velocity to the programming device. The said velocity can be determined by numerical signal differentiation from the boom deflexion angle measurement system in the plane parallel to the floor. The boom deflexion velocity averaged per the cutting heads rotation was a bit of information used by the programming device to develop adjustment of the cutting process parameter value.

The analysis of automatic control system behaviour was grounds to introduce certain modifications to the setting system structure and settings. Besides entering information on the actual ongoing cutting heads movement velocity to the setting system, the following modifications were introduced:

1) the declared rated value of the torque achieved by the motor in the cutting system $M_{n}$ was increased from 400 to $600 \mathrm{Nm}$, 
2) the threshold value of the motor torque in the cutting system above which the dynamic overload $M_{p}$ takes place was increased from $2 \cdot M_{n}$ to $3 \cdot M_{n}$,

3 ) the range of the electro-hydraulic valve opening in the boom rotation actuator supply system $k_{D O}$ was changed from $(20 \div 90 \%)$ to $(30 \div 60 \%)$.

The choice of the first two out of the abovementioned parameters results not so much from the mechanical characteristics of the motor in the cutting heads drive but from the characteristics of the frequency inverter used to supply that motor. The inverters, being electronic devices, are characterised by high sensitivity even to short-term overload. Surges can cause overheating and damage of transistors in the converter system. This is why they are protected from excessive current rise. To counteract any undesirable switch-offs of the cutting heads drive by the protective system, the assumed rated level and the permissible dynamic overload of the drive are lower than the ones resulting from the motor parameters (for the used motor of $132 \mathrm{~kW}$, the rated torque is $851 \mathrm{Nm}$, while the critical torque is $3 \cdot M_{n}$ ). In the light of tests carried out using the actual facility, the values adopted initially, i.e. the rated value $\left(M_{n}\right)$ and the permissible dynamic load $\left(M_{p}\right)$, turned out too low and this is why they were increased.

Adjustment of the range of the electro-hydraulic valve opening in the boom rotation actuator supply system was to:

- shorten the start-up phase when making the cut by increasing the minimum valve opening at the cutting start,

- reduce the maximum boom deflexion velocity as the cut surface was rough after the cutting heads pass (with uncut ribs between the pick traces).

Figure 6 presents the values developed by the setting system and behaviour of the tested facility when cutting in the automatic control mode of cutting heads movements following the said modifications. Here, the cut with the web of cut $z=200 \mathrm{~mm}$ was carried out, with the initial height $h=150 \mathrm{~mm}$, when swinging the boom rightwards, within the boom deflexion angle in the plane parallel to the floor $\alpha_{H}$ from $-27^{\circ}$ to $+33^{\circ}$ (Fig. 6b). At the beginning of the discussed cut, the boom was deflexed vis-a-vis the floor plane at $\alpha_{V}=-11^{\circ}$. Despite identical initial values of the web of cut and height of both cuts discussed in this article, they were made in different conditions. This resulted from different boom deflexion in the plane parallel to the floor. Six seconds after cutting was started the setting system developed the maximum opening of the valve supplying the boom rotation actuator $\left(k_{D O R E F}=60 \%\right)$. However, the actual cutting heads movement speed $v_{O W}$ grew only to ca. 150 $\div 200 \mathrm{~mm} / \mathrm{s}$ (Fig. 6a). This resulted from cut height $h$ too high for the cut material and the properties of the hydraulic drive of the boom deflexion mechanism (the boom deflexion velocity depends on its load coming primarily from the cutting resistance). Growth in boom deflexion velocity was accompanied by the increased load of the cutting system. Consequently, the mean torque value on the main roadheader motor shaft $M_{m}$ exceeded 1,200 Nm in 12th second of cutting (Fig. 6c).
At the same time, the load dynamics of the roadheader cutting system grew, leading to the increased number of exceedances of the assumed threshold value $M_{p}$. When the number of exceedances was higher than 500, the setting system followed the control procedure for Case no. 4 (dynamic overload). However, in 11th test second, the number of exceedances of the threshold torque values fell below the above-mentioned value and an algorithm for Case no. 1 (excessive load) was implemented. The mean torque value on the motor shaft in the cutting heads drive $M_{m}$ was higher than $1.2 \cdot M_{n}$.

a)

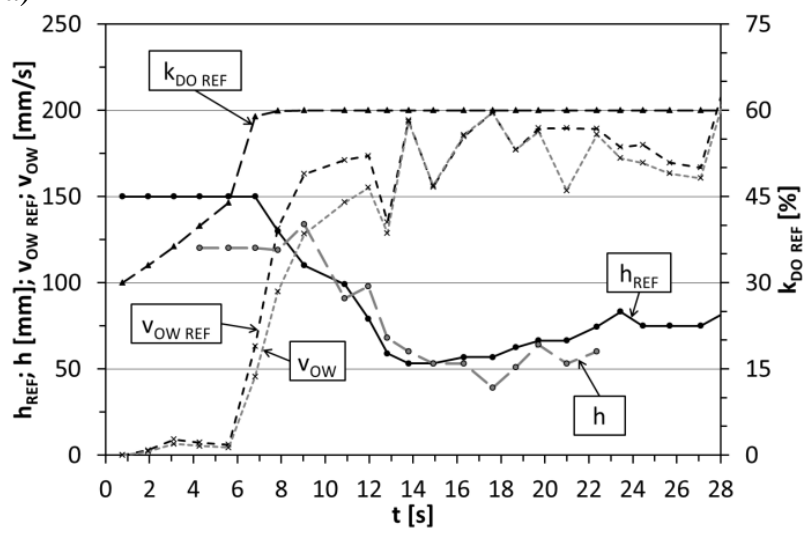

b)

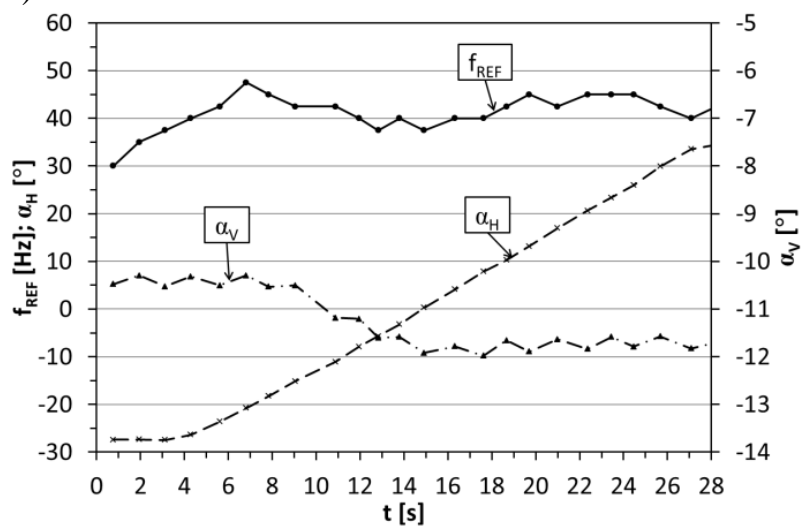

c)

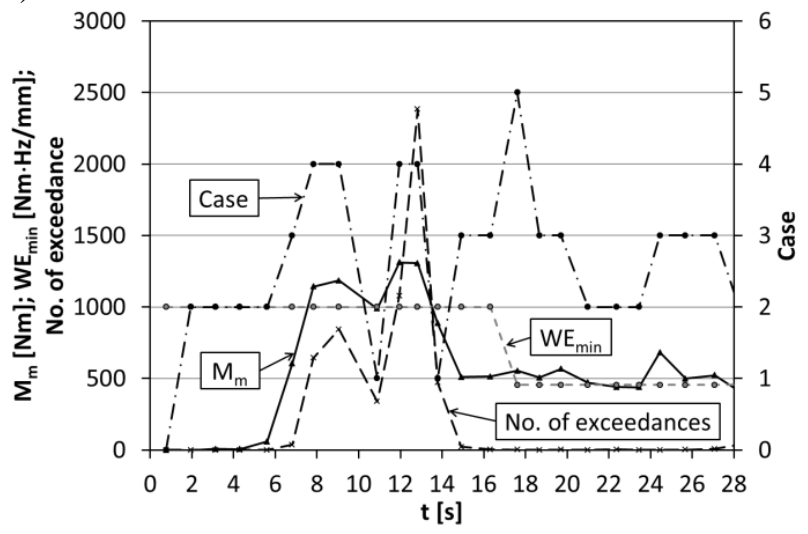

Fig. 6. Plot of cutting process parameter values developed by the setting system and behaviour of the tested roadheader when cutting in the automatic mode, considering the actual speed signal vow and following the programming device setting adjustment. 
Excess load of the cutting system resulted in changed boom deflexion angle in the plane perpendicular to the floor, leading to gradual decrease of the cut height $h$. This led to reduced cutting system load. Starting from 15 th second of the test to the end of the given cut, the cutting system remained in the rated load area (Case no. 3 ). The developed cutting process parameter values enabled also to minimize cutting energy consumption (Case no. 5).

In the examples presented in Fig. 5 and 6, the courses of the cut height values developed by the setting system $\left(h_{R E F}\right)$ and of the actual value $(h)$ obtained by scanning the cut surface before and after a given cut was made are shown. The reference value results from the assumed initial value (entered manually during the tests) and changing boom deflexion angle. It can be seen that the courses are highly convergent although the initial values differ as much as $25 \%$ (Fig. 6a).

\section{Summary}

The experimental studies of the actual facility proved many advantages offered by the developed automatic control system for movements of the roadheader cutting heads. The suggested control algorithm enables to obtain cutting efficiency much higher than for the manual control, ensuring beneficial dynamic load of the roadheader and significant reduction of cutting energy consumption. The mean cutting efficiency value in the automatic mode was 3 times higher when compared to the mean cutting efficiency in the manual control mode. Cutting energy consumption value obtained with automatic control was $50 \%$ lower than the one in the manual mode. As shown by the test results, appropriate control of the process parameters and ensuring programmed variability of the cutting heads angular velocity, enable to cut with high cutting heads movement speeds along the heading face, reducing the duration of excess dynamic load. In the manual mode - a high concentration of operating points in the range of low cutting heads movement speed (below $100 \mathrm{~mm} / \mathrm{s}$ ). For the automatic mode - a high share of operating points is focused in the velocity range $v_{O W}$ from 150 to $250 \mathrm{~mm} / \mathrm{s}$. They correspond to much lower cutting energy consumption values [11].

The tests carried out when cutting a cement and sand block of variable workability enabled to check control system behaviour and the response of the controlled facility in the process implementation conditions similar to the actual ones. The conclusions drawn from the analysis of results obtained enabled to fine-tune the setting system parameters. Moreover, it was found out that although the cutting heads movement speed control is carried out in the open feedback loop, it is necessary to monitor that speed. The actual values of that speed must be data required for the programming device to develop adjustments of the cutting process parameter values.

The work has been implemented under the research project titled "Control of roadheader cutting heads movement for reduction of energy consumption of mining and dynamic loads" co-financed by the Polish National Centre for Research and Development under the Applied Research Projects (agreement no. PBS3/B2/15/2015).

\section{References}

1. A. Klich (ed.), Machinery and equipment for underground construction engineering (Śląsk Publishing House, 1999) (in Polish)

2. Roadheader in tunneling - today's state-of-the-artroadheader. https://tunnelingshortcourse.com/2016presentations/owens-roadheader-tunneling.pdf (access date: 08.06.2018)

3. D. Townes, US Department of Transportation Federal Highway Administration. https://www.fhwa.dot.gov/construction/3d/amg/pubs /hif14009.pdf (access date: 11.06.2018)

4. J. Lyly, S. Hartwig, G. Nord, Proceedings of the 63. BERGTEKNIKDAGEN (2018)

5. S. Hang, N. Shurong, G. Jun, The Open Automation and Control Systems Journal 7, (2015)

6. D. Jasiulek, J. Świder, PAR Magazine 1, (2013)

7. The World of Wirtgen - Cold Milling Machines. https://media.wirtgen-

group.com/media/02_wirtgen/media_1/media_1_01 _cold_milling_machines_2/media_1_01_cold_milli ng_machines_2_00_general_information/W_brochu re_Cold-Milling-Machines_0316_EN.pdf (access date: 11.06 .2018 )

8. J. Jonak, J. Gajewski, Transport Przemysłowy i Maszyny Robocze 4 (2011) (in Polish)

9. J. Jonak, J. Rogala-Rojek, Maszyny Górnicze, 29, 1, 29-33 (2011) (in Polish)

10. M. Dolipski, P. Cheluszka: Dynamics of the roadheader's cutting system (The Silesian University of Technology Press, 2002) (in Polish)

11. P. Cheluszka, P. Sobota, Proceedings of $23^{\text {rd }}$ International Conference on Methods and Models in Automation and Robotics 211-216 (2018)

12. P. Cheluszka, M. Dolipski, P. Sobota, Mining Informatics, Automation and Electrical Engineering 2, 59-68 (2017) 